\title{
¿Una mancha de sangre en la vía chilena al socialismo? Muerte de militantes de partidos y agrupaciones políticas en tiempos de la Unidad Popular
}

\section{A blood stain in the Chilean road to socialism? Death of militants of parties and political groupings in times of Popular Unity}

\section{FRANCISCO JAVIER MORALES AGUILERA Universidad Autónoma de Madrid \\ Becario CONICyT \\ franciscoj.morales@estudiante.uam.es}

Resumen: La muerte de militantes políticos durante la época de la Unidad Popular (1970-1973) constituye todavía un tema complejo dentro de los estudios dedicados a reexaminar dicha experiencia. Apoyándose en distintas fuentes documentales, este trabajo ha podido constatar quince casos de militantes fallecidos a lo largo de estos años, siendo mayoritariamente la acción de terceros el factor determinante a la hora de explicar cada muerte. En este artículo, se reconstruyen las circunstancias y contextos de algunos de estos casos, tratando de explicar hasta qué punto dichas muertes impactaron tanto en la escena política de cada colectividad como dentro de algunos debates más generales sobre el gobierno de Salvador Allende.

Palabras claves: Chile, Unidad Popular, violencia política.

Abstract: The death of political activists during the Popular Unity years in Chile (19701973 ) is a complex issue in the studies that reexamine the period. Based on different documentary sources, this study verifies fifteen cases of militants killed during these years, the majority due to the action of third parties. The article reconstructs the circumstances and contexts of some of these cases in order to explain the effects of these deaths on their respective political communities and on contemporary debates about Salvador Allende's government.

Keywords: Chile, Popular Unity, political violence.

Recibido: 28 de septiembre de 2018; aceptado: 1 de marzo de 2019; publicado: 30 de septiembre de 2019. Revista Historia Autónoma, 15 (2019), pp. 171-188 


\section{Introducción}

Al abordar las muertes de connotación política durante los años de la Unidad Popular (UP) en Chile, las imágenes tienden a centrarse en dos o tres de los casos más reconocibles, a saber: el del exministro democratacristiano Edmundo Pérez Zujovic en 1971 o la del edecán naval del presidente Allende, Arturo Araya, ocurrida a fines de julio de 1973. Estos nombres, sin embargo, constituyen sólo una parte de las víctimas que fallecieron en el transcurso de la vía chilena al socialismo.

A partir de una revisión de prensa y de otras fuentes documentales, este trabajo ha podido constatar una cifra de quince militantes de partidos y agrupaciones políticas muertos en los casi tres años de la Unidad Popular. En catorce de los quince casos consignados, la muerte de estos militantes se debió a la actuación de terceros que, a través del uso de armas de fuego, eliminaron físicamente a quien veían, muy posiblemente, como un enemigo político. Tales homicidios, por cierto, se insertaron tanto en contextos de agitación y enfrentamiento callejero, de origen diverso, como en el marco de un plan premeditado de asesinato. Como se verá más adelante, la excepción a la tendencia antes descrita la constituyó únicamente un militante que murió por la acción de la policía uniformada en la ciudad de Concepción.

Por razones de espacio, este artículo se centrará en seis casos y no en la totalidad de militantes que fallecieron, aunque la referencia sobre el resto de las muertes será inevitable a efectos de reconstruir algunas coyunturas ${ }^{1}$. Es pertinente aclarar inmediatamente que aquellos individuos que militaban en organizaciones como el Movimiento de Izquierda Revolucionario (MIR) o el Frente Nacionalista Patria y Libertad (FNPL) también son considerados en este estudio, pues se trata ante todo de movimientos políticos.

Estas primeras ideas remiten a la pregunta de por qué es importante abordar un fenómeno de estas características. En primer término, porque se trata de un campo no del todo explorado por la historiografía chilena, la cual ha centrado el análisis en otros aspectos del gobierno socialista como el rol de los partidos políticos, las relaciones internacionales y el papel de los trabajadores, entre otros tópicos ${ }^{2}$. Es cierto que en algunas obras se ha abordado este fenómeno y el de la violencia política en general, aunque bajo una mirada muy parcial y marcadamente ideológica, buscando endosar la responsabilidad de dichas muertes al gobierno y sus bases

\footnotetext{
${ }^{1}$ Los quince militantes de movimientos políticos muertos durante la Unidad Popular son los democratacristianos Juan Millalonco, Edmundo Pérez Zujovic, Jaime Contreras Iglesias y Enrique González Menares; los miembros del MIR, Arnoldo Ríos Maldonado, Eladio Caamaño y Nilton Da Silva; los militantes comunistas José Pino Navia y José Ahumada Vásquez, los militantes de Patria y Libertad: Héctor Castillo Fuentealba y Mario Aguilar Rogel; los socialistas Román Lara Ponce y Heriberto Villalobos Fuentes y el militante del Partido Nacional Rolando Matus. Dentro de este grupo de militantes políticos fallecidos cabría mencionar el caso de Oscar Balboa Elgueta miembro del Movimiento Patriótico de Regeneración (MOPARE) integrado por transportistas partidarios del gobierno de la Unidad Popular.

${ }^{2}$ Una excepción a esta tendencia la constituyen autores como Goicovic, Igor, "Temas y debates en la historia de la violencia política en Chile", en Contenciosa, 3 (2014), pp. 1-16.
} 
militantes $^{3}$. Además, la mayor parte de estos trabajos es tributaria de aquella tesis de origen militar — y con la cual se justificó el golpe militar — que responsabilizaba a la izquierda por el clima de violencia que se vivió antes del 11 de septiembre de $1973^{4}$. Tal vez sea este uso que algunos autores han hecho del tema lo que ha influido en que otros historiadores sean reacios a abordarlo en toda su complejidad y amplitud.

En un trabajo anterior abordamos de modo inicial el tema de las muertes de connotación política durante los años de la UP, enfocándonos en los últimos meses de existencia de dicho gobierno y consignado los casos de algunas víctimas que no se incluyen aquí ${ }^{5}$. De modo que el presente artículo es una ampliación más consistente sobre el tema, tanto temporal como temáticamente, al tiempo que vincula su importancia y proyección a discusiones más de fondo sobre el carácter y recorrido de la vía chilena al socialismo.

A partir de estas coordenadas, sostenemos que la muerte de militantes políticos durante la Unidad Popular, además del impacto previsible para los actores involucrados, fue vinculada, por los propios partidos y movimientos políticos, a una parte de las discusiones más generales que se dieron en torno al carácter y trayectoria de la vía chilena al socialismo. Así por ejemplo, tras la muerte del estudiante del MIR Eladio Caamaño en Concepción el día 12 de mayo de 1972, a manos de la policía uniformada, el movimiento al que pertenecía la víctima hizo un duro cuestionamiento sobre el rol de los aparatos represivos y de las autoridades civiles encargadas de resguardar el orden público, al tiempo que reflexionaba en torno al verdadero carácter que tenía un gobierno que se asumía como democrático, socialista y popular, pero que ahora se veía involucrado en la muerte de un joven estudiante. Como vemos, la muerte de militantes se podía instalar, desde la óptica de los actores, rápida y efectivamente como parte de un discurso estratégico - tanto opositor como oficialista - que sirviera para condenar o endosar responsabilidades respecto al problema de la violencia política y otros tópicos generales.

El impacto previsible que dichas muertes tuvieron en la escena pública, aunque se tratase de un número limitado de casos, pueden entenderse a partir de ciertos elementos. Por ejemplo, que las muertes de militantes estuvieron vinculadas a contextos más amplios de polarización y enfrentamiento - con varios heridos y detenidos - los cuales recibían, como es de suponer, una mayor atención por parte de la prensa. Adicionalmente cabría señalar que estas muertes no fueron casos referidos a una sola colectividad política, o el producto de una persecución planificada en contra de determinadas ideologías o tendencias. Por el contrario, los partidos y

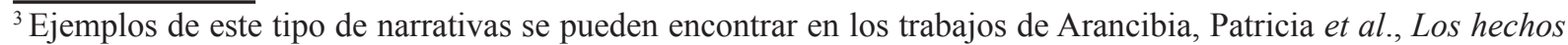
de violencia en Chile: del discurso a la acción, Santiago, Universidad Finis Terrae-Instituto Libertad y Desarrollo, 2003, e Ibáñez, Adolfo, Abrazado por la revolución: ideología y totalitarismo en Chile. 1960-1973, Santiago, Biblioteca Americana, 2004.

${ }^{4}$ Uno de los primeros textos en donde queda explicitada esta tesis corresponde al denominado Libro Blanco del cambio de gobierno en Chile, Santiago, Lord Cochrane, 1973.

${ }^{5}$ Morales, Francisco, "Muerte de civiles en contextos de violencia política urbana. Casos, dinámicas y espacios en los últimos meses de la Unidad Popular", en Rolando Álvarez (editor), Actores sociales y conflicto político, Chile, siglo XX, Santiago de Chile, USACh, 2018, pp. 113-153.
} 
movimientos más importantes del periodo perdieron, todos, al menos un militante de sus filas, situación que permite, al menos tentativamente, indicar la transversalidad del fenómeno.

La reconstrucción de cada caso que este estudio consigna se hizo a partir de información de prensa, publicaciones oficiales de algunos partidos y movimientos, y de documentos provenientes de algunas entidades públicas, como el Servicio de Registro Civil y el Instituto Médico Legal. En el momento de escribir este artículo, el acceso a fuentes judiciales era bastante problemático. Se había solicitado en el Archivo Judicial de Santiago, a través del $34^{\circ}$ Juzgado del Crimen de Santiago, revisar algunos expedientes judiciales del periodo. Tras la espera de rigor se nos informó que probablemente dichos archivos estaban "perdidos" o que no habían sido hallados. De modo indirecto se pudo acceder a algunos expedientes, como en el caso del crimen del exministro Edmundo Pérez Zujovic ( ${ }^{\circ}$ 1986-70 del Segundo Juzgado Militar de Santiago) que se encontraba compendiado casi de forma completa en la Colección Histórica de Homicidios de la Policía de Investigaciones de Chile. ${ }^{6}$

La exposición de los contenidos de este artículo se inicia con una breve contextualización sobre la Unidad Popular que permita un posicionamiento histórico más inteligible. Enseguida se exponen algunas discusiones y debates sobre el gobierno de la UP y también, aunque de modo más específico, sobre el problema de la violencia política. El cuerpo central del artículo está estructurado en base a los seis casos que se han consignado: Rolando Matus, militante del Partido Nacional; Eladio Caamaño, integrante del MIR; Román Lara Ponce, adscrito al Partido Socialista; Héctor Castillo Fuentealba, miembro de Patria y Libertad; Enrique González Menares de la Democracia Cristiana y José Ahumada Vásquez, militante del Partido Comunista.

\section{Contexto y debates}

En su dimensión interna, el gobierno de Salvador Allende puede entenderse como la expresión más acabada del proyecto histórico de la izquierda chilena durante el siglo $\mathrm{xx}^{7}$. Es decir, una construcción de temporalidad extensa, cuyos orígenes se remontan a los años de formación del proletariado nacional y de organización de sus dos partidos eje (socialista y comunista), y que a fines de los sesenta incorporará a sectores cristianos y del centro político dentro de una gran plataforma programática. Es esta alianza, que hace confluir a importantes sectores del mundo obrero, campesino y poblacional con diversos cuadros dirigentes de los

\footnotetext{
${ }^{6}$ Policía de Investigaciones de Chile, "Homicidio de ex Ministro Pérez Zujovic", en Colección Histórica de Homicidios [en adelante, CHH] 1947-2008. Prefectura "Santiago" Brigada de Homicidios, 2 Tomos.

${ }^{7}$ Este énfasis es desarrollado en el texto de Winn, Peter, Tejedores de la revolución. Los trabajadores de Yarur y la vía chilena al socialismo, Santiago de Chile, LOM, 2004.
} 
partidos arriba señalados, la que llegará al poder en 1970, buscando transitar al socialismo a través de las pautas y formas institucionales de un estado demoliberal ${ }^{8}$.

Las discusiones sobre el rumbo que tomaría el proceso político en Chile a partir de ese momento y las lecturas y reflexiones que a posteriori se han hecho sobre él, constituyen un marco de discusión pertinente a la hora de entender dicho proceso y los elementos, tensiones y características que decantaron la muerte de cada militante. Expongamos brevemente algunas coordenadas bibliográficas.

Desde la mirada historiográfica más crítica sobre el gobierno de Allende se ha enfatizado recurrentemente en el tópico de la violencia política como el principal elemento descriptor del periodo9. Dicha interpretación sostiene que a partir de la década de los sesenta la izquierda chilena, influida por la Revolución Cubana, adscribió a una línea estratégica rupturista enarbolando la bandera de la lucha armada.

A partir de un ángulo interpretativo distinto, Tomás Moulián, recurriendo a la doble metáfora fiesta/drama inserta dicha experiencia dentro de lo que denomina como etapa de corporativismo político (1964-1973) ${ }^{10}$. El carácter festivo del gobierno de Allende estuvo determinado por una verdadera catarsis vindicativa de dimensión comunitaria, mientras que el drama lo está por la batalla política que se desarrolla y que terminará en derrota ${ }^{11}$. El papel que ocuparían los hechos de violencia, bajo el análisis de Moulián, podrían entenderse como eventos gatillados por un proceso revolucionario que transita, sin las herramientas teóricas ni factuales necesarias, para conducirse adecuadamente y delimitar dentro de un marco restringido la violencia.

Brian Loveman y Elizabeth Lira, en tanto, estructuran un análisis global sobre el tema de la violencia política en Chile abarcando los siglos XIX y $\mathrm{Xx}^{12}$. Ambos autores se detendrán en la violencia de carácter estatal que ha mantenido históricamente una relación conflictuada con aquella violencia subalterna que proviene desde la sociedad civil en un juego dialéctico que ha dejado una impronta característica en Chile. Eugenia Palieraki, también desde el estudio de la violencia política, pero específicamente aquella ocurrida durante la UP ${ }^{13}$, desplaza el punto de análisis desde lo que denomina la "guerra de las izquierdas" hacia la gran oposición interna que

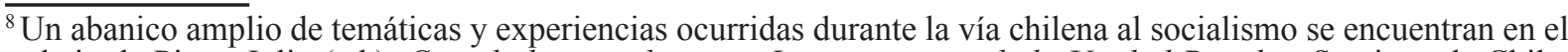
trabajo de Pinto, Julio (ed.), Cuando hicimos historia. La experiencia de la Unidad Popular, Santiago de Chile, LOM, 2005.

${ }^{9}$ Representante de esta corriente es Gonzalo Vial Correa, quien, a través de diversas publicaciones (libros, artículos, columnas de opinión y reportajes periodísticos), ha recalcado esta tesis. Véase, por ejemplo, Salvador Allende. El fracaso de una ilusión, Santiago, U. Finis Terrae, 2005, o los fascículos publicados en el vespertino La Segunda entre 1998 y 1999 titulados 1964-1973. La violencia pone a Chile al borde de la Guerra Civil. Incluso más, en 1991, Vial Correa fue el encargado de redactar el marco histórico del informe final de la Comisión de Verdad y Reconciliación que investigó las violaciones a los derechos humanos cometidas en Dictadura.

${ }^{10}$ Moulián, Tomás, La forja de ilusiones: El sistema de partidos, 1932-1973, Santiago de Chile, Akhileus, 2009.

${ }^{11}$ Ibídem, pp. 270-271.

${ }^{12}$ Lira, Elizabeth y Brian Loveman, "La violencia política en Chile: Contextos y prácticas desde 1810", en Jaksic, Iván y Juan Luis Ossa (eds.), Historia Política de Chile, 1810-2010. Tomo I Prácticas Políticas, Santiago de Chile, Fondo de Cultura Económica - UAI, 2017, pp. 361-392.

${ }^{13}$ Palieraki, Eugenia, "Las manifestaciones callejeras y la experiencia de la Unidad Popular (1970-1973)", en Pensamiento Crítico, 3 (2003), pp. 1-28.
} 
tuvo que enfrentar el gobierno. En dicho periodo, la violencia política, sobre todo la de carácter callejero, fue internalizada como medio de acción no sólo por los extremos, sino por casi todos los actores políticos del sistema, transformándose en un elemento central ${ }^{14}$.

Margarita Palacios, por su parte, visualiza este fenómeno a partir de la violencia política que se materializa tras el golpe militar desde un ángulo psicosocial ${ }^{15}$, entendiendo que el anticomunismo, verificado durante la UP, llegó a ser una expresión muy nítida de una ansiedad generalizada —y fantaseada- por acabar con é $1^{16}$.

Desde el espacio argentino, Marina Franco discute críticamente la utilidad de establecer una frontera entre democracia y dictadura a la hora de evaluar la intensidad de las violencias ocurridas antes y después de 1976, dado que su centralidad es transversal a los cambios institucionales ${ }^{17}$. España se sitúa también como un referente en temas de violencia política. Y lo es en virtud de su propia experiencia histórica, que acusa a lo largo de casi medio siglo problemas tan complejos como el del enfrentamiento civil, la represión o el terrorismo nacionalista, pero también porque ha logrado reflexionar profusamente sobre el mismo ${ }^{18}$.

¿Puede considerarse central entonces el tema de la violencia en Chile durante los años del gobierno socialista y, por ende, instalar en ese campo la muerte de militantes políticos? A partir de algunos elementos creemos que efectivamente ella es parte de un debate central dentro del espacio público. El primero de esos elementos se refiere a los discursos estratégicos. Como advirtiera Palieraki, el tema de la violencia no era algo nuevo en Chile para 1970, ya sea porque algunos actores teorizaron sobre ella incorporándola a sus estrategias discursivas o porque otros advirtieron que no solo podía ser parte constitutiva de un curso de acción determinado, sino que también estaba desplegada, por ejemplo, en la acción del Estado y sus aparatos coercitivos. Un segundo elemento se refiere a las prácticas concretas de violencia, presentes tanto en su dimensión institucional como subalterna y que ciertamente no se configuraron únicamente con la llegada de la UP al gobierno, pues eran preexistentes. Convendría agregar únicamente que, para estos años en particular, el acento debiera estar puesto en la interacción entre violencias subalternas o civiles, es decir, entre actores políticos que en ciertas coyunturas se encuentran abiertamente enfrentados, evidenciando un modo particular de leer y asumir la contingencia política $^{19}$.

\footnotetext{
${ }^{14}$ Ibídem, p. 11

${ }^{15}$ Palacios, Margarita, “A psychosocial interpretation of political violence: Chile 1970-1973”, en Psychoanalysis, Culture \& Society, vol. 16, 3 (2011), pp. 244-260, DOI «https://doi.org/10.1057/pcs.2010.21».

${ }_{16}^{16}$ Ibídem, pp. 246-247.

${ }^{17}$ Franco, Marina, Un enemigo para la nación. Orden interno, violencia y “subversión”, 1973-1976, Buenos Aires, Fondo de Cultura Económica, 2012.

${ }^{18}$ González Calleja, Eduardo, "La contribución de Julio Aróstegui al debate historiográfico sobre la violencia política en la España contemporánea”, en Hispania Nova, 12 (2014).

${ }^{19}$ Esta particular forma de entender el proceso político desde un espacio subalterno se encuentra, por ejemplo, en Gaudichaud, Franck, Poder popular, participación de los trabajadores y Cordones industriales. Testimonios sobre la dinámica del movimiento popular urbano durante el gobierno de Salvador Allende, Santiago, LOM, 2004.
} 


\section{Exposición de casos}

\subsection{Muerte en el campo: el crimen de Rolando Matus}

El 17 de abril de 1971, en un espacio semirrural cercano a Temuco se produjo un grave incidente entre agricultores a raíz de la "toma" ilegal de unos terrenos. Según El Diario Austral, elementos pertenecientes al Movimiento Campesino Revolucionario (MCR) apoyaron una ocupación ilegal en terrenos del agricultor Otto Gruner. Cuando éste y sus empleados se percataron del hecho, a eso de las 05:30 de la madrugada del día 17, comenzó un violento altercado que pronto derivó en un intercambio de disparos que se extendió por cerca de treinta minutos $^{20}$. Como resultado de esta acción, continúa el medio, cayeron heridas seis personas, siendo Rolando Matus Castillo el más afectado, falleciendo días después, el 19 de abril, en horas de la mañana ${ }^{21}$. En una óptica similar describió los hechos el periódico Tribuna, voz casi oficial del P. Nacional, acusando directamente al MIR de balear a Matus Castillo cuando éste se opuso a la toma de terrenos. Asimismo, el matutino criticaría el "notorio desconocimiento de la realidad" del ministro del Interior, José Tohá, a propósito de las declaraciones que hiciese en orden a negar la existencia de grupos armados extremistas en las zonas agrícolas ${ }^{22}$. La versión de El Siglo enfatizó la responsabilidad que le cabía a un grupo de latifundistas por oponerse a la Reforma Agraria, desatando lo que a su juicio eran una serie de "agresiones patronales"23 en diversas zonas rurales del país. La muerte de Matus era indicativa de un fenómeno que no podía calificarse de marginal, pues los enfrentamientos en espacios rurales a propósito de la Ley de Reforma Agraria no era algo nuevo en el país. Desde la aprobación de esta normativa jurídica en el gobierno anterior, las relaciones entre los grupos que habitaban el campo chileno - y que descansaban sobre una jerarquía vertical y en extremo tradicional - se trastocaron profundamente. Bajo la Unidad Popular, este fenómeno se haría más conflictivo en virtud de la expansión de la reforma y el incremento sostenido de la movilización social, sobre todo con la acción de grupos y brigadas que buscaban acelerar la expropiación y redistribución de tierras. Adicionalmente, la contrarrespuesta del gremio latifundista a efectos de oponerse a la aplicación de la ley también contribuyó en la polarización del proceso ${ }^{24}$.

\footnotetext{
20 "Encargan detención de homicida de Lautaro", en El Diario Austral, 18 de abril de 1972, p. 9.

${ }^{21}$ El Certificado de defunción de la víctima constata como causa de muerte una anemia aguda por herida a bala penetrante abdominal. Servicio de Registro Civil e Identificación [en adelante, SRCeI], folio 44260084, registro E, 1971.

22 "Asesinado por balas miristas cayó agricultor que defendió su tierra", en Tribuna, 20 de abril de 1971, p. 14.

23 “6 latifundistas detenidos por agresión armada en Curarrehue”, en El Siglo, 19 de abril de 1971, p. 6.

${ }^{24} \mathrm{El}$ mundo rural chileno, y en particular algunos de los conflictos desarrollados a propósito de la puesta en marcha de la Reforma Agraria, ha sido retratado por autores como Tinsman, Heidi, La tierra para el que la trabaja. Género, sexualidad y movimientos campesinos en la Reforma Agraria chilena, Santiago de Chile, Lom-Centro de Investigaciones Diego Barros Arana, 2009.
} 
Como es de suponer, la muerte de Matus no sería la última vinculada a los espacios rurales, pues existieron varios casos similares a este ocurridos a lo largo de la Unidad Popular. En un número no menor, dichas víctimas fueron los propietarios de los fundos que se oponían a la materialización de la reforma, fuese por vía legal o de facto, en sus tierras. Lo ocurrido con Matus es interesante pues, a diferencia de otros casos, aquél era un reconocido militante de una agrupación política, en este caso del Partido Nacional, que pasó a ser un "testimonio vivo" para los compañeros de partido, quienes honraron su muerte formando la Brigada Rolando Matus. Ésta, como se recordará, sería un grupo de choque que actuaría, tanto en espacios rurales como urbanos, enfrentándose periódicamente a los grupos de izquierda más activos. Así, por ejemplo, tendría una destacada participación custodiando, junto a miembros de Patria y Libertad y de la JDC, la marcha de mujeres realizada el 1 de diciembre de 1971 y que derivó con el paso de las horas en violentos incidentes. Como se ve, un accionar algo distante a la imagen casi idílica que tenía el entonces presidente del Partido Nacional, Sergio Onofre Jarpa, para quien la mencionada brigada "[...] solo era un grupo de muchachos preparados para realizar tareas de resguardo de sedes y reuniones" ${ }^{\prime 25}$.

Dentro de estos primeros meses del gobierno de la UP también fallecieron otros militantes de partidos y agrupaciones políticas. Estos fueron los casos de Arnoldo Ríos, militante del MIR, y los democratacristianos Juan Millalonco y Edmundo Pérez Zujovic ${ }^{26}$.

Como era de esperar, dichos crímenes pusieron un temprano signo de interrogación respecto al carácter que asumiría el proceso político de transición al socialismo que llevaba adelante la UP. Desde el oficialismo se había asegurado de que la vía chilena se apoyaría en una estrategia pacífica y democrática para alcanzar sus objetivos. Sin embargo, desde la oposición, y al parecer con un evidente uso político de los hechos, se sostuvo que estos crímenes cuestionaban tal formulación, sobre todo porque los autores materiales de aquellos fueron elementos ligados a la izquierda.

\footnotetext{
${ }^{25}$ Arancibia, Patricia et al., Jarpa. Confesiones políticas, Santiago de Chile, La Tercera-Mondadori, 2002, p. 171. ${ }^{26}$ Arnoldo Ríos Maldonado, estudiante universitario del MIR, fue muerto en Concepción el 2 de diciembre de 1970 a manos de brigadistas pertenecientes muy posiblemente al Partido Comunista. Las repercusiones de dicho caso fueron rápidamente apaciguadas a raíz de un acuerdo político extrajudicial entre las colectividades involucradas. Para detalles de este caso véase, "Del Pleno político al plano del sectarismo", en Punto Final, 8 de diciembre de 1970, pp. 6-7; “Falleció estudiante herido en incidentes en Concepción”, en El Siglo, 3 de diciembre de 1970, p. 1. Juan Millalonco, en tanto, era un militante activo de la Juventud Democratacristiana (JDC) de la ciudad de Puerto Aysén, en el sur del país. En la madrugada del día 4 de abril de 1971se produjo un confuso incidente en la sede del P. Socialista desde donde, según algunos testimonios, se repelió a balazos el ataque que perpetraron elementos de la JDC. En dicha refriega, Millalonco recibió un disparo en el tórax que le causaría la muerte. Sobre este caso véase, El Llanquihue, 5 de abril de 1971, p.5. Finalmente, ocurrió el crimen de Edmundo Pérez Zujovic, destacado dirigente de la DC y exministro del Interior del gobierno de Eduardo Frei Montalva. El 8 de junio de 1971 un comando de extrema izquierda denominado Vanguardia Organizada del Pueblo (VOP) asesinó a balazos a Pérez Zujovic mientras éste conducía su automóvil particular en el sector oriente de la capital. Hasta el día de hoy existen dudas respecto a los verdaderos propósitos e ideología de este grupo. Se ha insinuado, incluso, que el crimen habría sido instigado por la CIA, que tenía infiltrado a dicho grupo, aunque también se debe precisar que desde la propia VOP se justificó dicho crimen por considerar que Pérez Zujovic, en su calidad de ministro del Interior durante el gobierno de la DC, había sido responsable de la matanza de campesinos en Pampa Irigoin en 1969. Sobre este caso véase, "Alevoso asesinato de Edmundo Pérez Zujovic", en La Prensa, 9 de junio de 1971, p 1.
} 
3.2. ¿Violencia represiva o choque de masas? La muerte de Eladio Caamaño

El 12 de mayo de 1972 se produjeron en Concepción graves incidentes entre manifestantes de izquierda con la fuerza pública, los que terminarían con la muerte del estudiante Eladio Caamaño Sobarzo, militante del FER (brazo estudiantil del MIR) ${ }^{27}$. El Intendente regional Wladimir Chávez, de filiación comunista, había autorizado para esa jornada una marcha de la oposición por el centro de la capital penquista. Ante ello, los sectores de izquierda agrupados en torno al eje PS-MIR, de fuerte presencia en la zona, decidieron copar la calle ese mismo día a efecto de disuadir y contrarrestar el impacto de la marcha opositora. Era de esperarse, en ese contexto, una batalla campal entre grupos rivales, no obstante, los incidentes más graves se produjeron entre los sectores de izquierda y la policía uniformada que trató de impedir el avance de éstos por el centro de la ciudad.

Según diversos medios y testimonios, Caamaño fue golpeado en reiteradas ocasiones por Carabineros lo que produjo su muerte en el Hospital de Concepción. Un testigo citado por el periódico El Sur, señalaría que Caamaño logró eludir la represión de Carabineros en un primer momento para luego volver a la refriega, frente a la Plaza de los Tribunales, donde fue nuevamente alcanzado por la policía recibiendo una segunda golpiza ${ }^{28}$. El Siglo, en tanto, planteó una versión distinta al señalar que Caamaño falleció a consecuencia de la "vandálica" acción de Patria y Libertad al enfrentarse a la ultraizquierda. Tal descripción se apoyaba en las palabras del subsecretario del Interior, Daniel Vergara, quien había sostenido que los instigadores y provocadores de los incidentes habían sido precisamente elementos de la ultraderecha y la ultraizquierda ${ }^{29}$.

La posición del MIR fue significativa a este respecto porque en sus declaraciones quedaron explicitadas algunas de las discusiones y tensiones más estructurales que recorrían al conjunto de la izquierda chilena. Fue el secretario general de esta colectividad, Miguel Enríquez, quien, al explayarse sobre estos tópicos, acusó al Gobierno de ordenar la dura represión de la movilización de izquierda, actuando, en cambio, tibiamente con la marcha de la oposición ${ }^{30}$. El resultado de ello, continuó Enríquez, fue un centenar de detenidos, la mayoría de izquierda, heridos de diversa consideración y "un compañero muerto". Luego, entraría en los temas de fondo que parecían "agrietar" a la izquierda: falseamiento de los hechos y carácter represor del gobierno popular; las críticas del PC al ultraizquierdismo; reformismo versus revolución;

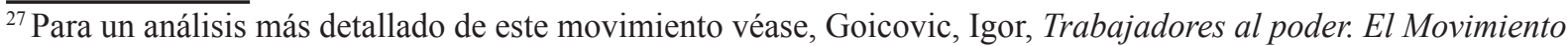
de Izquierda Revolucionaria (MIR) y el proyecto revolucionario en Chile, 1965-1994, Concepción, Escaparate, 2016.

28 "Murió víctima de los incidentes", en El Sur, 14 de mayo de 1972, p. 11. Este mismo medio indica que Caamaño era estudiante del Liceo 3 y confirma su militancia en el FER.

29 "Irresponsabilidad criminal", en El Siglo, 14 de mayo de 1972, p. 1.

${ }^{30}$ Estos aspectos ya habían sido enfatizados en el denominado Manifiesto de Concepción; una declaración conjunta que el PS, MAPU, IC y MIR habían firmado el 24 de mayo al objeto de entregar su versión de los hechos ocurridos el día 12. Véase, "El Manifiesto de Concepción”, en Punto Final, 6 de junio de 1972, p. 5 y ss.
} 
el papel de la movilización de masas dentro del proceso de cambios, entre otros aspectos ${ }^{31}$. Bajo la óptica de Enríquez, todos estos temas, por muy estructurales o teóricos que fuesen, se habían materializado en los incidentes ocurridos el día 12 de mayo. Siguiendo la lógica del líder mirista, la muerte de Caamaño reflejaba el carácter represor del Estado, mientras que la postura y reacción del PC era prueba indesmentible de su animadversión, casi obsesiva, en contra del “ultraizquierdismo". Según Enríquez, la recuperación de la autonomía de los aparatos represivos se debía a la creciente debilidad del Gobierno, que prefería censurar los “excesos" de las fuerzas populares antes que criticar las acciones represivas de la policía ${ }^{32}$.

Todo esto graficaba, en fin, tanto el nivel que había alcanzado el conflicto político en las calles, agudizado desde fines de 1971, como también las divisiones en el seno de la coalición oficialista y de la izquierda en general. A diferencia de lo ocurrido en diciembre de 1970 con la muerte del también mirista Arnoldo Ríos, se veía muy difícil un acuerdo expedito entre el PC y el MIR para destrabar el conflicto.

\subsection{Román Lara Ponce: ¿Una víctima del fascismo criollo?}

Tres meses después de ocurrido el crimen del joven mirista se produjo, también en el marco de violentos incidentes callejeros, la muerte del militante socialista Román Lara Ponce en la ciudad de Los Ángeles. En la tarde del día 22 de agosto, un grupo de individuos pertenecientes a Patria y Libertad, organizó una manifestación en el sector céntrico de dicha ciudad al objeto de protestar por la política económica del gobierno. La versión del vespertino socialista Las Noticias de Última Hora, sostiene que varios campesinos partidarios del gobierno decidieron intervenir en dicha protesta produciéndose entonces un enfrentamiento de proporciones entre ambos grupos. En un momento de la refriega — continúa el periódico - los militantes nacionalistas sacaron "armas de fuego" y atacaron al grupo de campesinos, cayendo herido de gravedad Román Lara, quien fallecería en la madrugada del día $23^{33}$. El subsecretario del Interior, Daniel Vergara, confirmó que otras tres personas quedaron heridas, además de un carabinero que prestaba servicios de resguardo del orden público. Al día siguiente, el periódico arriba citado reprodujo una declaración pública del PS en donde se señalaba que dicha colectividad pediría la aplicación de la Ley de Seguridad Interior del Estado en contra de los dirigentes de Patria y Libertad, al tiempo que llamaba a sus militantes a estar en "estado de alerta" para, llegado el momento, salir en defensa del Gobierno ${ }^{34}$.

El diario El Sur concordó en que la muerte de Lara se produjo en el marco de incidentes entre grupos rivales. No obstante, refiere que su muerte se produjo por golpes y no por la

\footnotetext{
${ }^{31}$ Farías, Víctor, La izquierda chilena 1969-1973. Documentos para el estudio de su línea estratégica, tomo 3, Berlín, CEP, 2000, pp. 2373-2389.

${ }^{32}$ Ibidem, p. 2377.

33 "A balazos fue muerto un obrero agrícola", en Las Noticias de Última Hora, 24 de agosto de 1972, p. 24.

34 "Ley de Seguridad Interior contra Patria y Libertad", en Las Noticias de Última Hora, 25 de agosto de 1972, p. 3.
} 
acción de armas de fuego. En la misma nota se indicó que en paralelo a los hechos que le costaron la vida al militante socialista, un grupo de individuos partidarios del gobierno apedreó las oficinas de la Radio Agricultura quebrando vidrios y dañando las instalaciones del estudio de grabación ${ }^{35}$. En su edición del viernes 25 de agosto, este periódico también consignó las declaraciones que diversos dirigentes socialistas realizaron en el funeral de Román Lara, las cuales coincidieron en honrar el sacrificio de la víctima en defensa del gobierno, al tiempo que se sindicó de forma taxativa a Patria y Libertad como los autores materiales del crimen, quienes, en palabras del ministro Hernán del Canto, “constituían la cara del fascismo que los militantes socialistas no dejarían pasar" ${ }^{\prime 3}$.

Los énfasis en las declaraciones arriba consignadas daban cuenta, implícitamente, de discusiones más generales sobre el proceso político en curso. En este caso en particular, fue el propio partido en que militaba la víctima el que instaló este caso dentro de un marco de tensión más amplio, caracterizado por lo que consideraban un asedio permanente hacia el gobierno y sus bases militantes. Estas últimas lejos de adoptar una postura de contención y apaciguamiento debían estar en actitud vigilante para defender al gobierno. Se puede percibir que en el espacio público de mediados de 1972 ya estaban presentes algunas discusiones en torno a la continuidad y pervivencia del proyecto de la Unidad Popular, ya fuese por los énfasis opositores que explicitaban un enfrentamiento abierto en contra de aquél como también por los diagnósticos que, desde un ángulo defensivo, hiciera el conjunto de la izquierda.

\subsection{El primer mártir nacionalista. La muerte de Héctor Castillo Fuentealba}

Cuando un complejo 1972 parecía quedar atrás se produjo en el sur del país la muerte del militante de Patria y Libertad, Héctor Castillo Fuentealba. Los hechos que decantaron la muerte de Castillo ocurrieron en Chillán el miércoles 20 de diciembre de 1972, cuando se daban a conocer los resultados electorales de la Federación de Estudiantes de la sede regional de la Universidad de Chile ${ }^{37}$. Los cómputos favorecieron a la oposición, lo que significó el inicio de escaramuzas y pugilatos entre diversos grupos al interior del campus universitario. Rápidamente la situación se salió de control y derivó en violentos incidentes que se extendieron más allá de la Universidad, alcanzando las principales arterias de la ciudad. Los principales medios de prensa escrita coincidieron en que la muerte de Héctor Castillo Fuentealba se produjo en el contexto de estos incidentes y por la acción de terceros ${ }^{38}$.

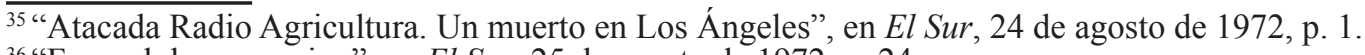

36 "Funeral de campesino", en El Sur, 25 de agosto de 1972, p. 24.

${ }^{37}$ En este caso se encuentra abordado también en Morales, Francisco, "Muerte de civiles... op. cit., p. 128.

${ }^{38}$ El certificado de defunción de Castillo señala como causa de muerte herida de bala en el hemitórax derecho.

SRCeI, folio $15721006, \mathrm{~N}^{\circ}$ de inscripción $1.001,1972$
} 
Para El Mercurio fueron elementos de la Unidad Popular quienes atacaron unilateralmente a Castillo en pleno centro de Chillán ${ }^{39}$. El periódico local La Discusión sostuvo que fueron individuos no identificados quienes haciendo uso de armas de fuego dieron muerte a la víctima a una distancia de 200 metros del recinto universitario ${ }^{40}$. El Siglo acusó al nacionalismo frentepatrista como responsable del crimen (una especie de ajuste de cuentas por luchas intestinas dentro de la propia organización) ${ }^{41}$.

A fin de mes, la revista oficial de Patria y Libertad, junto con un completo relato de los hechos, haría un sentido homenaje a su militante fallecido ${ }^{42}$. Adicionalmente, los énfasis, que dentro del frente nacionalista apuntaban a explicitar y desarrollar sin ambages los recursos defensivos y eventualmente violentos en contra de los grupos de izquierda, cobraron mayor fuerza y protagonismo. José Díaz indica que, a partir de la muerte de Castillo, el entrenamiento en artes marciales e instrucción paramilitar dentro del FNPL se intensificaron notoriamente ${ }^{43}$. En otras palabras, Patria y Libertad visualizaba que la muerte de su militante se encadenaba a una serie más amplia de hechos (enfrentamientos callejeros y disputas por el espacio público) que tenían como hilo conductor estar vinculados a una lucha frontal en contra del gobierno al objeto de lograr su caída.

Mirado en su conjunto, las muertes de los militantes verificadas en 1972 vinieron a reforzar las líneas discursivas que los partidos y movimientos ya habían comenzado a definir en los meses anteriores.

En el caso del MIR, que volvía sufrir la muerte de un militante — esta vez de su brazo estudiantil, el FER - , se reforzó la idea en torno a las contradicciones del proceso socialista chileno y la forma en cómo reencauzar el mismo. De hecho, a raíz de la muerte de un poblador a manos de la policía en agosto de 1972, el MIR volvió a referir los argumentos ya reseñados con anterioridad ${ }^{44}$, entendiendo que no se trataba de un hecho aislado, sino por el contrario estaba vinculado a otros hechos de sangre en que las fuerzas populares y del MIR habían sido duramente reprimidas, mientras que la responsabilidad de algunas instituciones y partidos, en especial del PC, no se había aclarado.

Para los socialistas, que habían sufrido la muerte del militante Román Lara, se debía poner atajo cuanto antes a la acción violentista de los grupos opositores a la UP a partir precisamente de la movilización popular. Para Patria y Libertad, en tanto, la muerte de su militante constituía

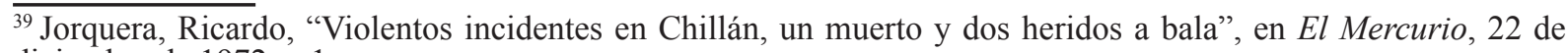
diciembre de 1972, p.1.

${ }^{40}$ La Discusión, 22 de diciembre de 1972, p. 2.

41 "Carta abierta de Altamirano a Frei: "En este país el único intocable es el pueblo"”, en El Siglo, 22 de diciembre de 1972 , p. 3.

42 "Héctor Castillo Fuentealba. Primer mártir nacionalista asesinado por un marxista", en Patria y Libertad, 28 de diciembre de 1972, p. 1.

${ }^{43}$ Díaz, José, Patria y Libertad. El nacionalismo frente a la Unidad Popular, Santiago de Chile, Centro de Estudios Bicentenario, 2015, p. 184.

44 “El MIR a los obreros, campesinos, pobladores, estudiantes soldados y al pueblo de Chile”, 11 de agosto de 1972, en Farías, Víctor, La izquierda chilena 1969-1973. Documentos para el estudio de su línea estratégica, tomo 4, Berlín, CEP, 2000, p. 2957.
} 
una prueba irrefutable del carácter armado y totalitario que trasuntaba el proyecto socialista. La óptica del PN orbitaba también en una dirección similar, mientras que la DC comprendía que se estaba en presencia de un marco político complejo en donde no cabían posiciones graduales ni matizadas, sino confrontar con firmeza al gobierno. Bajo estas perspectivas se afrontaría la compleja coyuntura electoral de marzo de 1973, precedida, como veremos, de una violentísima campaña entre las brigadas y comandos de cada partido ${ }^{45}$.

\section{5. “QQuién lo mató? Los marxistas prepotentes”. El caso de Enrique González Menares}

A mediados de marzo de 1973 y una vez que la coyuntura electoral quedaba paulatinamente atrás, se produjo la muerte del democratacristiano Enrique González Menares. Los hechos ocurrieron en una zona semiurbana en el sector oriente de la capital, específicamente en la avenida Echeñique a la altura del número 7.800. Al amanecer del 16 de marzo dos jóvenes —el ya citado González Menares junto con Sergio Vergara Contreras - fueron heridos mortalmente a balazos mientras custodiaban una parcela. Al igual que en otros casos, la prensa tuvo distintas interpretaciones de lo ocurrido.

Para los medios oficialistas se trató de un ataque contra los pobladores del campamento Carlos Cortes, ubicado al lado de la parcela donde se encontraban González y Vergara. Según El Siglo, González y Vergara, junto a elementos del grupo PROTECO (Protección Comunal) y de la Brigada Rolando Matus, atacaron con armas de fuego a algunos pobladores que levantaban una mediagua en el campamento antes mencionado. Los atacantes - continúa El Sigloincrementaron sus disparos al tiempo que dos de ellos ingresaron violentamente al lugar donde estaban los pobladores, lo que significó quedar en la zona de fuego de sus propios compañeros siendo alcanzados finalmente por las balas ${ }^{46}$. La Tercera, en tanto, sostuvo que González y Vergara dormían en una carpa al interior de la parcela tras cumplir funciones de vigilancia nocturna. Habría sido un menor de edad quien, al percatarse que algunos sujetos habían derribado la cerca de alambres de púas, comenzó a gritar y despertar a quienes pernoctaban en el lugar. Se inició entonces - continúa el matutino - una lluvia de piedras que pronto derivaría en un ataque armado en contra de los cuidadores de la parcela con el resultado de las dos víctimas fatales ya señaladas ${ }^{47}$. El Mercurio desarrolló una línea interpretativa similar al sostener que González y Vergara fueron acribillados por elementos extremistas que se encontraban situados en la parcela contigua y en el campamento Carlos Cortés ${ }^{48}$. La Prensa afirmó que fueron sujetos pertenecientes a la CORMU (Corporación de Mejoramiento Urbano) quienes ametrallaron a

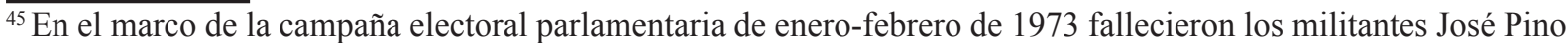
Navia (PC) y Jaime Iglesias Contreras (DC). Véase, "Momios ultimaron a militante comunista", en El Siglo, 8 de enero de 1973, p. 1, y "Otro asesinato cometió la Brigada Ramona Parra", La Prensa, 20 de febrero de 1973, p. 9. 46 "Dos muertos en agresión fascista a pobladores", en El Siglo, 17 de marzo de 1973, p. 3.

47 "Con ráfagas de metralleta asesinaron a dos menores que arrendaban una parcela", en La Tercera, 17 de marzo de 1973, p. 26.

48 "Sangriento asalto a pobladores", en El Mercurio, 17 de marzo de 1973, p. 1.
} 
los jóvenes vigilantes luego de asaltar y tomarse el terreno. Según este medio, los disparos se hicieron sin mediar discusiones ni amenazas de ningún tipo ${ }^{49}$.

Para el subsecretario del Interior, Daniel Vergara, se trató de un crimen doloroso y lamentable que enfrentó a pobladores de parcelas de la CORMU sin ahondar en mayores detalles. Tan escueta declaración fue comentada acremente por el senador de la DC, José Musalem, quien sostuvo que el mayor instigador de lo sucedido, al "iniciar las tomas de terreno" era el Subsecretario del Interior: “[...] es el autor moral de todos los hechos que están ocurriendo hoy en día", concluyó Musalem ${ }^{50}$. Tales declaraciones buscaban relacionar la muerte del joven militante a una cadena de infortunios más amplia, vinculados, por cierto, a la materialización del programa de la UP. Desde esa perspectiva, los responsables no eran individuos anónimos ocultos tras la bruma de un enfrentamiento confuso, sino que, al contrario, eran los dirigentes políticos del oficialismo en tanto conductores del proceso político y responsables, en última instancia, del accionar de los partidarios del gobierno. Para el recuerdo quedarían los gritos con que la JDC despediría a González Menares el día de su funeral. Las decenas de militantes que se reunieron el 17 de marzo gritarían con entusiasmo a lo largo del cortejo: "Camarada Enrique González ¡Presente! ¿Quién lo mató? ¡Los marxistas prepotentes!”51.

Este hecho marca un punto de continuidad respecto al contexto que se venía desarrollando en el país, bajo el entendido de que las muertes arriba descritas estuvieron determinadas por situaciones de abierto enfrentamiento entre grupos rivales. Para los partidos que se vieron involucrados en estos sucesos, la muerte de sus militantes constituyó un hecho vinculable directamente al proceso social y político en curso. Desde el PC, recordemos, se acusaba la existencia de una escalada fascista en marcha que buscaba eliminar a los partidarios de la UP que opusieran resistencia a sus planes. Desde la Democracia Cristiana, en cambio, el responsable principal era el gobierno, el "autor moral" como indicara el senador José Musalem en referencia al subsecretario del Interior, Daniel Vergara. Las culpabilidades estaban, en fin, endosadas siempre al bando opuesto, ya sea por una declaración en particular o alguna una acción o medida que se adoptase y que significaba una actitud reactiva a la misma. Esta última, por cierto, independiente de su nivel de violencia siempre era consecuencia de un hecho anterior que la había desencadenado, por lo que a los ojos de sus ejecutores estaba de algún modo justificada.

\subsection{Crimen en el centro de la capital. La muerte de José Ahumada Vásquez}

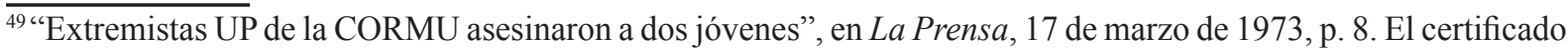
de defunción de la víctima anota como causa de muerte una herida a bala abdominal complicada y anemia aguda consecutiva. SRCeI, folio 14726332, $\mathrm{N}^{\circ}$ de inscripción 332, 1973.

50 "Violencia en La Reina", en La Tercera, 17 de marzo de 1973, p. 2.

51 "Incidentes durante el cortejo provocó el PS", en La Tercera, 18 de marzo de 1973, p. 2.
} 
Este crimen ocurrió en el contexto de los desórdenes callejeros que desde el día 25 de abril se habían vuelto periódicos en el centro de la capital ${ }^{52}$. El día 27 de ese mes, en horas de la tarde, una numerosa columna de obreros y estudiantes inició una marcha por la principal arteria capitalina. Al pasar frente a la sede de la Democracia Cristiana se iniciaron los enfrentamientos que derivaron en la muerte del obrero comunista José Ahumada Vásquez a causa de un disparo. El hecho, junto con causar una profunda conmoción entre los asistentes a la marcha, dio pie para que la prensa nacional señalase distintas interpretaciones.

Como era de esperar, El Siglo cubrió ampliamente la noticia por casi una semana. En su edición del 28 de abril señaló que las ráfagas de metralleta que mataron a Ahumada provinieron desde la sede del PDC en momentos en que los obreros de la construcción y del Cordón Cerrillos pasaban frente a dicho edificio. "Los asesinos — indicaba el matutino- prácticamente fusilaron a los obreros disparando una metralleta y revólveres desde el cuarto piso" ${ }^{53}$. En la prensa opositora se pudieron observar algunos matices. El Mercurio no minimizó la muerte del trabajador toda vez que informó detalladamente de lo ocurrido e incluso en su portada dio cuenta de la víctima fatal. En sus páginas interiores se consignaron las distintas versiones existentes: desde la que responsabilizaba como victimarios a miembros de la DC hasta aquella que sostenía que los manifestantes lanzaron piedras a la sede política lo que habría generado la actuación de Carabineros quienes procedieron a disparar al aire ${ }^{54}$.

La Prensa, matutino perteneciente a la DC, intentó desviar la atención de los hechos. En su portada del día 28 de abril señalaba: Suplantadas las Fuerzas Armadas y Carabineros. El país entregado a las hordas rojas. En una esquina inferior un titular que resultaba inquietante: Mataron a cadenazos a liceana DC en Quillota. En la parte central de la portada el titular principal: Asaltada y baleada sede central del PDC. Más abajo, en tanto, otro titular sugerente: Disparos y piedras contra "La Prensa" "55. Recién en las páginas interiores de este rotativo se consignó, aunque de forma muy breve, la existencia de un fallecido quien según el periódico "[...] cayó frente a los árboles situados frente a la sede del PDC" ${ }^{\prime 6}$. No deja de ser significativa la forma en cómo este medio abordó el fallecimiento del obrero comunista. La supuesta muerte de una liceana en Quillota, a manos de un grupo de extremistas de la UP — como señalara este medio - resultaba ser una información desconcertante y de alto impacto. Sin embargo, este mismo medio reconocería días después que tal noticia había sido un error, pues solo se trató de un incidente menor, sin víctimas fatales. Por cierto, dicho desmentido se hizo en un minúsculo recuadro de una página interior ${ }^{57}$.

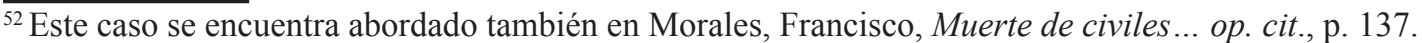

53 "Un obrero asesinado a balazos desde la sede central del PDC", en El Siglo, 28 de abril de 1973, p. 9.

54 "Un muerto en los incidentes", en El Mercurio, 28 de abril de 1973, p. 1.

55 "Suplantadas las Fuerzas Armadas y Carabineros. El País entregado a las hordas rojas", en La Prensa, 28 de abril de 1973, p. 1.

56 "Disparos y piedras", en La Prensa, 28 de abril de 1973, p. 5.

57 “Desmentida muerte de estudiante”, en La Prensa, 30 de abril de 1973, p. 5.
} 
Si bien existieron explicaciones encontradas de lo sucedido, la versión que entregase la DC en el sentido de que José Ahumada fue asesinado por sus propios compañeros resulta discutible. Si ello hubiese ocurrido así, quienes rodeaban a la víctima podrían haber visto al atacante o al menos escuchar el origen del disparo. Se podría haber arrestado incluso al responsable del hecho. Tampoco es del todo creíble la posibilidad de que el atacante haya sido un Carabinero. Si la policía realizó disparos al aire resulta difícil que la bala impacte directamente en el tórax de la víctima como ha consignado su certificado de defunción ${ }^{58}$. Todo hace pensar que tras los incidentes producidos en las afueras de la sede de la DC se produjo un áspero intercambio verbal entre los trabajadores y los militantes falangistas, algunos de los cuales estaban apostados en los balcones y pisos superiores de la sede, iniciándose entonces una refriega que incluiría piedrazos, agresiones con elementos contundentes y, por cierto, balazos. El subsecretario del Interior, Daniel Vergara, no dudaría en señalar que los autores de los disparos fueron "obviamente militantes de esa colectividad" $"$. Nótese que, en el caso de la DC, el énfasis estuvo puesto no en la muerte del obrero, sino que en los incidentes que precedieron dicho crimen, y que, bajo su óptica, eran el reflejo de que el país se encontraba a merced de las "hordas rojas", es decir, en una situación de virtual quiebre del estado de derecho. Las versiones encontradas de la prensa se mantuvieron por varios días más bajo un manto de mutuas recriminaciones, las cuales se vinculaban, como vimos, a discusiones más generales como el rol de las FFAA, la pervivencia del estado de derecho y otros. Significativo es constatar que la muerte de Ahumada también impactó en el mundo del arte y la cultura. En efecto, el pintor español José Balmes realizaría una serie de obras bajo el título José Ahumada Vásquez y que referían a la muerte del obrero. En una de estas obras se observa un cuerpo inerme derrumbado en el suelo, vestido completamente de negro y cuya parte superior está rodeada por un denso charco de sangre ${ }^{60}$.

El periodo mayo-agosto y los primeros días de septiembre de 1973 constituyeron la dramática antesala del golpe de estado ${ }^{61}$. Como sabemos, la mayor parte de los elementos que decantarían dicha salida se articularon con notable precisión. En el plano institucional, los poderes legislativo y judicial habían explicitado sendos pronunciamientos en contra del gobierno por su actuar — arbitrario e ilegal según aquellos - en distintas materias. Desde el mundo gremial se había organizado una nueva ofensiva que incluía a diversos segmentos de la producción, el comercio y los transportistas. En ambos casos, el propósito declarado era lograr, ya sin ambages, la caída del gobierno. En el oficialismo las cosas no marchaban mejor. La

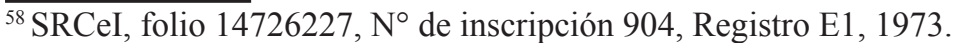

59 “51 detenidos por los incidentes del viernes", en El Mercurio, 29 de abril de 1973, p. 29.

${ }^{60}$ La obra se puede visualizar en el texto de Alonso, María Nieves, "José Balmes: Como un río que desborda sus orillas”, en Atenea, 489 (2004), pp. 139-147, DOI «https://doi.org/10.4067/S0718-04622004048900011».

${ }^{61}$ Fallecieron también en este periodo: Mario Aguilar Rogel de Patria y Libertad, véase; "Los asesinos a sueldo y los sepulcros blanqueados", en Patria y Libertad, 11 de mayo de 1973, p. 3; Nilton Da Silva del MIR, véase, Santa Cruz, Eduardo, "El fascismo chileno mató a combatiente brasileño", en Punto Final, 3 de julio de 1973, pp. 8 y 9; Heriberto Villalobos Fuentes, socialista, muerto en la ciudad de San Carlos, véase, El Comercio, 4 de agosto de 1973, p. 3, y Oscar Balboa Elgueta, militante del MOPARE. Véase, El Siglo, 19 de agosto de 1973, p. 1.
} 
existencia de dos bloques estratégicos dentro de la Unidad Popular, mutuamente excluyentes, marcaba una división profunda en su seno. Sumado a lo anterior cabría señalar la ola de atentados y desórdenes públicos que en esta etapa llegaron a su clímax. Como ha señalado acertadamente Luis Corvalán Márquez, desde el punto de vista político-institucional, para fines de agosto la izquierda estaba formalmente derrotada ${ }^{62}$. El golpe avanza a pasos agigantados.

\section{Conclusiones}

Las muertes de militantes que este estudio consignó no se sitúan como un fenómeno anexo o marginal respecto a procesos históricos de mayor envergadura. En dichos eventos, pudimos advertir una parte de las discusiones político-estratégicas más significativas de esos años, y también el impacto que generó el fallecimiento de algunos militantes para las propias filas de la colectividad.

Desde otro ángulo podría advertirse que la utilización recurrente de armas de fuego durante este periodo debió dejar una cantidad mayor de víctimas fatales y no un número que a primera vista parece ser tan reducido. Sin embargo, estos quince militantes fallecidos deben situarse en un marco de análisis más amplio en donde otros fenómenos y situaciones fueron igualmente relevantes. Por ejemplo, el de aquellas víctimas civiles, sin adscripción política, que también fallecieron en este periodo, o el de los heridos de gravedad por la acción de elementos contundentes que enfrentaban a grupos políticos rivales. Expongamos al respecto un dato que puede resultar revelador: entre octubre de 1972 y el golpe militar del 11 de septiembre se contabilizan cerca de 60 heridos a bala de gravedad en distintos puntos del país ${ }^{63}$. Igual de indicativo es el contenido del informe que el entonces ministro del Interior Carlos Prats dio a conocer respecto a los incidentes producidos entre el 6 y el 31 de enero de 1973, es decir, en plena campaña electoral con vista a los comicios de marzo. En dicho documento se detallan, entre otras cifras, cincuenta heridos de diversa consideración, treinta atentados de connotación política contra sedes y personas y cerca de quince detenidos por portar armas de fuego ${ }^{64}$. Como se puede advertir, las muertes de estos militantes están vinculadas tanto a contextos particulares como a otras manifestaciones de violencia política del periodo.

Sobre las reacciones de cada colectividad se pueden señalar algunas líneas generales. En el caso de la DC, la muerte de sus camaradas sirvió para reafirmar su óptica en torno que en

\footnotetext{
${ }^{62}$ Corvalán, Luis, Los partidos políticos y le golpe del 11 de septiembre, Santiago de Chile, Universidad Bolivariana, 2000, p. 381.

${ }^{63}$ Las referencias de publicaciones periódicas para la reconstrucción de dichos casos en, Morales, Francisco Javier, "Muerte de civiles... op. cit., p. 148.

64 "Resumen de incidentes con motivo de la próxima elección parlamentaria. Periodo del 6 al 31 de enero de 1973", en Prats, Carlos, Memorias. Testimonio de un soldado, Santiago de Chile, Pehuén, 1985, pp. 359 - 360.
} 
el país operaban grupos armados ilegales ligados a la extrema izquierda los cuales actuarían criminalmente ante cualquier confrontación con grupos opositores. Como vimos, este fue el énfasis que intentó destacar desde un primer momento el sector conservador de la DC, ligado a la figura del expresidente Frei Montalva. En el caso del MIR se observó una situación más compleja. En dos de las tres muertes de sus militantes la responsabilidad no recayó en grupos rivales sino, por el contrario, en la propia izquierda y el gobierno de la UP. Ello reafirmó el discurso mirista en torno a que los enemigos de la clase obrera no se encontraban únicamente en la burguesía y la oposición, sino también en el sectarismo que impregnaba el accionar de ciertos partidos (en particular, al PC) y en el carácter históricamente represivo del Estado chileno. Para el PC y el PS, se trataba de una escalada reaccionaria que buscaba además de la eliminación física de la clase popular abrir paso a un golpe de estado que derrocara al gobierno de Allende. Para el PN y Patria y Libertad, por su parte, los homicidios de sus militantes eran un reflejo del accionar siniestro de las "hordas marxistas" que se encaminaban a instaurar una dictadura totalitaria, dejando a su paso una ola de extremismo y violencia.

Conviene agregar, para finalizar, que dentro de los procesos de reestructuración ideológica ocurridos tras el golpe militar se procedió a construir, por parte del mundo castrense, una tesis particular en torno al problema de la violencia durante la Unidad Popular. Tal argumentación señalaba, en líneas generales, que la izquierda chilena era la única responsable por el cuadro generalizado de violencia política que allí se produjo, y por extensión, de las víctimas que fallecieron, destacándose siempre aquellos casos de sujetos que pertenecían a la oposición (Pérez Zujovic, Rolando Matus, entre otros). Ello se utilizaría, por cierto, como un elemento más para justificar el golpe de estado. No obstante, los elementos y casos abordados en este artículo demuestran la transversalidad de la violencia política de aquel entonces, con un número de víctimas similares tanto en la oposición como en las filas oficialistas. Ello, como es de suponer, constituye el reflejo de problemas más profundos que, en ningún caso, pueden atribuirse únicamente a un actor o tendencia en particular. Todo lo anterior, amerita, para futuras investigaciones, una reflexión más acabada sobre el carácter y trayectoria de la violencia en Chile, sus temporalidades de mediana y larga y duración y los énfasis que sirvieron de soporte discursivo para su justificación y desarrollo. 